\title{
Exercitando o olhar, apurando o ouvir: notas etnográficas sobre relações de gênero em uma escola pública de Petrópolis (RJ)
}

\author{
Girlaine Weber ${ }^{1}$ \\ Débora Breder ${ }^{2}$ \\ Universidade Católica de Petrópolis
}

Resumo: Este artigo apresenta resultados parciais de pesquisa realizada em uma escola pública da Rede Municipal de Petrópolis, estado do Rio de Janeiro, sobre relações de gênero. A partir de um olhar etnográfico - ou seja, teoricamente informado e que compreende a etnografia como uma 'descrição densa' de relações sociais e simbólicas -, buscamos analisar os mecanismos invisíveis da construção hierárquica da diferença masculino/feminino, visando entender de que forma a escola (re) produz socialmente, em sua organização espaço/temporal e em suas práticas pedagógicas, os construtos de gênero.

Palavras-chave: escola; relações de gênero; práticas pedagógicas; etnografia.

\footnotetext{
${ }^{1}$ Mestre em Educação pela Universidade Católica de Petrópolis e pesquisadora do Grupo de Estudos em Educação, Cultura e Contemporaneidade (GRECCA/UCP).

${ }^{2}$ Doutora em Antropologia pela Universidade Federal Fluminense com estágio doutoral na École des Hautes Études en Sciences Sociales. Professora do Programa de Pós-Graduação em Educação da Universidade Católica de Petrópolis e pesquisadora do Grupo de Estudos em Educação, Cultura e Contemporaneidade (GRECCA/ UCP), do Grupo de Reconhecimento de Universos Audiovisuais (UFRJ) e do Grupo de Análises de políticas e Poéticas Audiovisuais (GRAPPA/UERJ).
} 


\title{
Exercising the look, clearing the hear: ethnographic notes on gender relations in a public school in Petrópolis (RJ)
}

\begin{abstract}
This article presents partial results of a research carried out in a municipal public school of Petrópolis, state of Rio de Janeiro, on gender relations. From an ethnographic view, that is, theoretically informed and which understands ethnography as a 'dense description' of social and symbolic relations, we seek to analyze the invisible mechanisms of the hierarchical construction of male/female difference, in order to understand how the school socially (re)produces, in its space/temporal organization and in its pedagogical practices, the constructs of gender.
\end{abstract}

Keywords: School. Gender Relations. Pedagogical Practices. Ethnography.

\section{Ejercitando la mirada y el oir: notas etnográficas sobre las relaciones de género en una escuela pública de Petrópolis (RJ)}

\begin{abstract}
Resumen: Este artículo presenta resultados parciales de la investigación llevada a cabo en una escuela pública en la red municipal de Petrópolis, estado de Río de Janeiro, sobre las relaciones de género. Desde una perspectiva etnográfica - es decir, teóricamente informada y que comprende la etnografía como una "descripción densa" de las relaciones sociales y simbólicas - buscamos analizar los mecanismos invisibles de la construcción jerárquica de la diferencia masculino/feminino, con el objetivo de entender cómo la escuela (re) produce socialmente, en su organización espacio/temporal y en sus prácticas pedagógicas, las construcciones de género.
\end{abstract}

Palabras clave: Escuela. Relaciones de Género; Prácticas Pedagógicas. Etnografía 
(...) je pense qu'aujourd'hui beaucoup de divisions qui, chez les Kabyles, étaient reproduites par l'ordre masculin, la division de l'espace, etc., sont reproduites par l'intermédiaire du système scolaire qui est un des lieux de reproduction des catégories de construction de la différence entre les sexes (...).

Pierre Bourdieu (2002)

$\mathrm{E}$ m sua belíssima descrição da casa kabyle, Pierre Bourdieu (1999) nos mostra o quanto a simbólica sexual é estruturante na constituição tanto de seus espaços internos e externos, quanto de seus usos sociais. A construção hierárquica da diferença masculino/feminino que, na cosmologia das sociedades mediterrâneas, opera a partir de uma série de oposições homólogas, como cultura/natureza, quente/frio, seco/úmido, duro/mole, fora/dentro, claro/escuro, alto/baixo, manifesta-se desde a parte alta da casa - luminosa, lugar dos humanos, do fogo, do tear, de todas as atividades propriamente culturais; espaço por excelência do masculino - até a parte baixa - escura, úmida, lugar dos animais e das atividades naturais, como o sexo, o parto e a morte; espaço eminentemente feminino.

Mas isso não é tudo: estruturando a divisão do espaço da casa e de seus usos sociais, a simbólica sexual estrutura também a divisão das atividades entre homens e mulheres, do que é permitido e proscrito a eles e elas segundo uma lógica simbólica cuja evidência proviria da estreita correspondência entre as estruturas objetivas e as estruturas mentais. Como nota o autor, quando apreendemos o mundo estruturado de determinado modo, estando as estruturas subjetivas em consonância com as estruturas objetivas, nós o percebemos como algo evidente, absolutamente "natural" (BOURDIEU, 2002).

O que o autor chama de a "dominação masculina" constituiria, justamente, parte dessa ordem assentada na construção simbólica da diferença masculino/feminino, que não obstante o caráter singular que apresenta nas mais diversas culturas, como a dos berberes da Cabília, por exemplo, manifestar-se-ia, invariavelmente, segundo uma lógica binária e hierarquizada que transforma a diferença sexual - arbitrário natural - em valor - arbitrário cultural. Deste modo, a percepção da materialidade do corpo e da diferença sexual transforma-se em discurso implícito que justifica a dominação masculina:

\footnotetext{
A força particular da sociodiceia masculina lhe vem do fato de ela acumular e condensar duas operações: ela legitima uma relação de dominação inscrevendo-a em uma natureza biológica que é, por sua vez, ela própria uma construção social naturalizada. (BOURDIEU, 2003: 33)
}

Em sua perspectiva, a dominação masculina constituiria uma das formas mais extremas da violência simbólica, justamente por ser aquela que mais inevitavelmente passa pelo corpo - por seu constrangimento, ameaça, coerção (BOURDIEU, 2002).

Constrangimento, ameaça, coerção que, nas sociedades ocidentais modernas, encontraria no sistema escolar um locus privilegiado para o seu exercício. Com efeito, para Bourdieu (2002; 2003), uma das instâncias reprodutoras das relações de gênero baseadas na visão androcêntrica de mundo seria a escola, legiti- 
mando-a, explícita e implicitamente, em ações políticas e práticas cotidianas. Práticas sociais que, não raro, nos passam completamente despercebidas de tão incorporadas em nossas práticas pedagógicas e esquemas de pensamento.

Considerando, pois, que a etnografia possibilita o estranhamento diante do que escapa a nossa percepção no dia a dia - ou como diz Bourdieu (2002), do que está no mais profundo e mais profundamente inconsciente da nossa experiência ordinária -, propusemo-nos realizar uma pesquisa etnográfica nesse universo que nos parece tão familiar: a escola.

Por etnografia compreendemos a "descrição densa" de relações sociais e simbólicas que se manifestam em práticas e discursos, conforme defende Clifford Geertz (2015). Não se trata de um "método", como ressalta o autor, mas de uma forma de conhecimento que demanda um esforço intelectual que envolve inextricavelmente a subjetividade do pesquisador, imerso nas relações que constituem seu próprio objeto de pesquisa.

Mas como não se perder nesse processo, como "objetivar-se indefinidamente", de "projetar no exterior frações sempre decrescentes de si", como tão bem expressou Claude Lévi-Strauss (1974: 26) na introdução à obra de Marcel Mauss?

Objetivar a própria subjetividade constitui um processo árduo e sempre inconcluso: requer um exercício constante de autorreflexividade, de problematização de nossa própria posição no campo e de nossa relação com o objeto de pesquisa em questão. Ou seja, requer uma autorreflexividade constante sobre as condições de produção dos nossos próprios dados de pesquisa (BOURDIEU, 2005).

Esse exercício, para nós, configurou-se como um processo penoso, acidentado e por vezes desolador, no decorrer do qual tropeçamos muitas vezes. Durante a pesquisa de campo, a escola que nos parecia tão próxima e familiar foi se tornando - à medida que íamos observando e tentando compreender as relações sociais e simbólicas que a constituíam (e nela nos posicionavam) -, de certa forma, um universo cada vez mais distante e estranho. Parecia que não mais reconhecíamos a escola nem nos reconhecíamos nela. Se como pesquisadoras o processo de estranhamento do que é familiar constitui um passo fundamental para a descrição densa do que não percebemos em nossa experiência cotidiana, como professoras com larga experiência no Ensino Fundamental não deixou de ser incômodo perceber, em nossas práticas pedagógicas e discursos, esses esquemas de pensamento que constroem a "evidência" do mundo.

Olhar e ouvir... Atos cognitivos que parecem tão simples, mas que constituem etapas fundamentais na pesquisa etnográfica (OLIVEIRA, 2000). Se foi com um olhar "teoricamente informado" que iniciamos nossa imersão no campo, observando as relações sociais e simbólicas que constituem a escola - como os usos sociais do espaço e a divisão sexual do trabalho -, foi com um ouvir "todo especial", procurando exercer a "escuta ativa" (BOURDIEU, 2012: 693-701), que aos poucos fomos apreendendo os sentidos atribuídos pelos nossos interlocutores a suas práticas sociais. Foi um trabalho paciente e contínuo, de vários meses, permanecendo por semanas a fio em cada espaço da escola: salas de aula, refeitório, cozinha, sala dos professores, pátio. Foi justamente essa repetição que nos permitiu perceber os mecanismos invisíveis de construção da diferença masculino/feminino na escola.

Como pondera Rose Mary Gerber (2013), é na repetição da observação e do convívio com nossos interlocutores que vamos apreendendo o sentido das ações mais corriqueiras - e o inesperado acontece: 
Considero que a etnografia se dá pela repetição. É repetir a observação, repetir a convivência, repetir momentos como se nada fosse acontecer e, de repente, tudo acontece. Fazer etnografia é estar presente de forma intensiva e repetitiva. É a repetição que permite viver a experiência densa que inclui o inesperado. (GERBER, 2013: 55)

Seguem, abaixo, algumas notas etnográficas fruto da pesquisa que desenvolvemos entre fevereiro de 2017 e junho de 2018 em uma escola pública situada na zona rural de Petrópolis, região serrana do estado do Rio de Janeiro. Pertencente à rede municipal, a escola oferece o primeiro e o segundo segmento do Ensino Fundamental para 380 alunos.

A localidade onde está situada a escola fica a pouco mais de quarenta quilômetros do centro histórico da cidade e caracteriza-se, economicamente, pela produção de hortifrutigranjeiros, um pequeno comércio, artesanato e a fabricação de doces. Sua população é de pouco mais de 10 mil habitantes. O clima ameno e a paisagem típica da Serra dos Órgãos atraem veranistas em busca de caminhadas ecológicas, banhos de cachoeira e cavalgadas. A principal via de acesso é pavimentada e as secundárias ainda se mantém em terra batida, o que ocasiona dificuldade de tráfego nos períodos de chuva, dificultando a locomoção dos alunos (WEBER, 2018).

\section{Exercitando o olhar: a escola, seus espaços e ritos}

Sete horas da manhã. Crianças e jovens, a maioria uniformizados, descem dos ônibus escolares parados na calçada da escola3. Alguns chegam caminhando sozinhos ou acompanhados por parentes, de carro, moto ou bicicleta.

O acesso ao prédio escolar não é o mesmo para todos: os alunos entram pelo portão lateral da escola, passam por um corredor, concentrando-se no pátio. Já os professores entram pela porta central - estilo neoclássico, almofadada, bandeira envidraçada com pequena grade de proteção e coloração azul - e os funcionários de apoio pela entrada de serviço.

Se o acesso à escola não é o mesmo para todos, tampouco seus espaços internos: na entrada de serviço, local onde fica armazenado o lixo da escola, há um espaço revitalizado - o solário, ambiente claro e decorado com cores alegres para os funcionários almoçarem, realizarem pequenos lanches e descansarem no horário do almoço. Mas apenas os funcionários de apoio o utilizam: cozinheiras, auxiliares de serviços gerais, zeladores, inspetores e garis. Os docentes não frequentam esse espaço: ficam na área interna, na sala dos professores que, diferentemente do solário, é um espaço pequeno, pouco iluminado, com paredes encardidas pelo tempo e o assoalho gasto. A sala também é frequentada pelos inspetores de disciplina e zeladoras em desvio de função - funcionários cujas tarefas estão diretamente relacionadas à disciplinarização dos alunos. O fato, contudo, incomoda visivelmente os docentes, que não raro alegam falta de liberdade para tratar determinados assuntos devido ao compartilhamento da sala, que lhes é destinada, com outros funcionários. Questão abordada, inclusive, em um conselho de classe.

Da entrada de serviço à sala de professores, o espaço escolar revela hierarquias sociais. Mesmo que não haja placas informando "proibido a entrada ou a circulação de pessoas", esses espaços possuem, simbolicamente, um acesso restrito segundo as diferentes posições dos sujeitos, evidenciando relações de poder

3 Por meio da LDB $n^{0}$ 9394/96, em seu artigo 208, VII, foi garantido aos alunos residentes em área rural o transporte escolar gratuito, regulamentado pela Lei $\mathrm{n}^{\circ} 10.880 / 04$. 
geralmente pouco percebidas na escola. Dentre as quais, as relações de gênero.

Ao tocar a sirene, os alunos começam a formar as filas que vão separando-os por segmento, ano de escolaridade e sexo: meninos para um lado, meninas para o outro. O objetivo da divisão é a "organização da escola", segundo a diretora.

Por determinação legal, as escolas da rede pública são obrigadas a tocar o hino nacional4. Quando, por esquecimento, não se toca o hino, os alunos logo percebem, interrogando: "e o hino?!" Alguns se recusam a ficar na fila e cantar, iniciando os primeiros conflitos do dia entre a disciplina escolar e os corpos indóceis das crianças e jovens - que resistem, pulsam, insistem em existir segundo seu próprio ritmo. Depois de cantar o hino, são encaminhados por uma funcionária para as salas de aula.

As salas de aulas, amplas, com pé direito alto, assoalho em estado precário, têm enormes janelas que, entretanto, não são abertas porque "abrir demais as janelas dispersa os alunos e não se consegue manter a disciplina", explica uma professora. As carteiras são enfileiradas e organizadas em dupla e cada aluno tem seu lugar marcado na sala. "Cada indivíduo no seu lugar; e em cada lugar, um indivíduo", como diria Michel Foucault (2014: 140) referindo-se ao quadriculamento do espaço nas instituições disciplinares. Não há recursos tecnológicos ou jogos; apenas livros didáticos e alguns de literatura infanto-juvenil. Em quase todas as salas há cartazes cujo objetivo é controlar o comportamento dos alunos por meio de vários recursos, como o uso das cores verde/vermelho em uma espécie de "semáforo do comportamento" (verde: "muito bom"; vermelho: "preciso melhorar") e "estrelinhas" (indicando a pontuação das crianças), hierarquizando-os em uma escala disciplinar. Os meninos lideram o ranking dos alunos classificados como aqueles que possuem "mau comportamento" - um dado também observado em outras pesquisas, como nota Carvalho (2004: 13), referindo-se a estudos realizadas tanto no Brasil quanto no exterior.

A equipe gestora, formada pela diretora geral, diretora adjunta e orientadora escolar, supervisiona o encaminhamento dos alunos para as salas de aula. A diretora geral passa o dia envolvida nos afazeres administrativos, mas é constantemente interrompida para resolver conflitos entre professores e alunos. Os professores encaminham os alunos considerados indisciplinados, dentre os quais muitos com defasagem idade/ano escolar - e em sua maior parte, meninos -, para a sala da direção alegando que os mesmos se recusam a fazer as atividades, implicam com outros colegas, não largam o celular e os agridem verbalmente. Esses alunos se defendem dizendo que o professor fica na sala "com o celular também" e "só passa dever chato".

Dentre esses alunos destaca-se um grupo de jovens, entre 13 e 17 anos - onze meninos e apenas uma menina - que se recusam a frequentar a sala de aula. Eles têm muito em comum: estão na escola há anos; são reprovados sob alegação de "mau comportamento"; e provêm de famílias com baixo capital cultural e econômico. Esses alunos, que não possuem o capital linguístico que a escola exige e ainda não conseguem ler fluentemente. Circulam pelo ambiente escolar durante as aulas: sobem nos galhos mais altos das árvores, entram no porão, escalam o forro, pulam o portão da escola e logo depois retornam por conta própria. O lugar menos frequentado por esses jovens, que perambulam por toda a escola explorando seus espaços, é a sala de aula.

Quem são eles? No decorrer da pesquisa convivemos mais intensamente com

${ }_{4}^{4}$ Lei Federal n. 12.031, de 2009, que determina que as escolas públicas e privadas incluirão obrigatoriamente em sua rotina, pelo menos uma vez por semana, a execução do Hino Nacional. 
o grupo do turno da manhã. Manoel, 17 anos, não consegue expressar-se oralmente com desenvoltura e recebe de outros alunos o apelido de "cheiroso", o que gera diversos conflitos entre ele e os que assim o chamam5. João, 17 anos, quase não conversa com os professores e funcionários da escola; quando questionado permanece de cabeça baixa e é monossilábico em suas respostas - sua mãe, quando chamada na escola age do mesmo modo. Saul, 16 anos, também se expressa de forma monossilábica - assim como o pai, quando fala com a equipe gestora. Rodrigo, 16 anos, quando precisa falar, diminui o tom de voz e abaixa a cabeça. E Rafael, 16 anos, só interage com este grupo. No turno da tarde, Julia, 16 anos, é vista como "histérica" pelos funcionários por se descontrolar com facilidade durante os conflitos com os meninos. Em uma heteroatribuição de cor/raça, segundo os critérios de IBGE, a maioria desses "excluídos do interior", para usar uma expressão de Bourdieu (2015: 243), seria composta por negros e pardos.

O capital linguístico é privilegiado na escola: expressar-se com desenvoltura e riqueza de vocabulário é considerado quase como um "dom natural". Aquele que não o possui, que utiliza dialetos locais que traem sua origem de classe ou, como a fonoaudióloga que atende Manoel descreveu em seu laudo, tem "dislalia ambiental", é excluído do sistema escolar. Exclusão esta que prescinde da expulsão tout court, materializando-se por meio da violência simbólica - violência tanto mais eficaz quanto mais invisível se mostra. "Ele não sabe falar, como vai aprender?”, pergunta repetidamente uma professora, sem dar-se conta que é justamente a reiteração da frase que a torna uma sentença praticamente fatídica.

Como nota Bourdieu (2002), referindo-se à dificuldade de expressão em situações de tensão social, comumente experimentada por indivíduos com certo habitus de classe:

(...) os dominantes culturalmente exercem também uma forma de dominação simbólica. Penso, por exemplo, na timidez. Todos os sócio-linguistas que, como Labov, estudaram a linguagem das classes populares em situação de tensão oficial, "formal”, como dizem os anglo-saxões, observaram que essa linguagem se quebra de certa forma. Não se deve concluir que eles não sabem falar, mas que há situações nas quais eles "perdem seus meios”, seu capital linguístico. (BOURDIEU, 2002: 232)

Mas se a voz não sai, os corpos falam: quando esses alunos são abordados pelos funcionários da escola e questionados, em voz alta, de forma autoritária “aonde vão?!”, "porque estão fora de sala?!”, "Vieram fazer o que na escola?!” , abaixam a cabeça e resmungam uma resposta qualquer, de forma quase inaudível.

O momento mágico, de alvoroço, surge quando soa a sineta: recreio, almoço ou hora de ir embora... O som da sineta anuncia uma ruptura, ainda que momentânea, num contínuo. Mas anuncia, também, o controle do tempo e a sanção normalizadora que se abate, de forma mais sentida, sobre o recreio, momento (supostamente) de maior liberdade dos corpos: os que se comportam segundo as normas recebem seu quinhão de recreio; já os que as infringem ficam em sala de aula. Por serem considerados mais indisciplinados, os meninos são geralmente os mais penalizados.

Recreio: os alunos saem da sala em fila dupla, uma para meninos e outra para meninas, e seguem para o pátio conduzidos pelas professoras. O pátio é descoberto, enorme, semelhante a um sítio, com árvores e grama necessitando de poda; como não há lixeiras, no fim do dia fica coberto com pacotes de biscoitos vazios. Eles correm e brincam, uns mais livremente, outros acompanhados e orientados

5 Todos os nomes foram alterados para resguardar a identidade de nossos interlocutores, alunos/as, professores/as e demais funcionários/as. 
pelas professoras.

$\mathrm{Na}$ área externa há uma quadra de esportes em condições precárias, sem uma das tabelas de basquete, traves sem redes e a tela de proteção danificada. Esse é o local em que os meninos passam a maior parte do tempo durante as aulas vagas e o recreio. Há momentos em que disputam o uso da quadra e a posse da bola. As meninas utilizam pouco a quadra, apenas em algumas aulas de Educação Física, ouvindo a orientação do professor com relação às regras do jogo. No entanto, quando o jogo de futebol, vôlei ou basquete tem início elas saem da quadra e ficam na arquibancada improvisada assistindo, conversando ou em silêncio, alheias, com fone de ouvido. A quadra constitui um espaço predominantemente masculino: nos momentos de lazer ela é ocupada pelos meninos que expõem suas habilidades para a plateia predominantemente feminina.

Almoço: o horário do almoço é sempre um momento tenso. Os alunos têm que permanecer em fila; porém, nem todos os corpos enfileirados permanecem dóceis - uns ficam empurrando, outros querendo cortar a fila. $\mathrm{O}$ inspetor de disciplina fica atento a qualquer movimento que os alunos façam, pois as regras são claras: não podem desperdiçar a comida colocada no prato, nem sair com a sobremesa do refeitório, o que gera inúmeros conflito entre alunos e inspetores.

O refeitório é amplo, bem iluminado e colorido. Tem um bebedouro, o único da escola, no qual ficam algumas canecas utilizadas por todos. Alguns alunos, contudo, se recusam a compartilhá-las e, ao solicitarem canecas limpas para a cozinheira, ouvem em alto e bom som: "enjoado!" Embora a refeição servida seja igual para todos, alunos, funcionários de apoio e corpo docente não comem juntos no mesmo horário e local. $\mathrm{O}$ quadro de apoio realiza suas refeições no solário e o corpo docente no refeitório, mas em horários distinto ao dos alunos. Há um buffet aquecido para utilização dos alunos, em self-service, mas ao contrário de sua finalidade, estes são servidos pelas cozinheiras com o objetivo de controlar o consumo, principalmente o de carne. Os meninos, meio acanhados, pedem mais carne e a cozinheira responde "tem pouco e todo mundo tem que comer".

Durante as filas ou sentados para as refeições, observamos meninos e meninas, dificilmente juntos, discutindo pelos mais diversos motivos - "você não tem educação, cortou fila" -, colocando apelidos, gritando e solicitando a presença dos professores e/ou do inspetor para resolverem a situação. O interessante é que se, à primeira vista, essas discussões, que também ocorrem no recreio, parecem constituir um conflito prestes a se transformar em briga entre meninos e meninas, ao observarmos mais detidamente percebemos que o imbróglio geralmente não passa de uma brincadeira com o objetivo de chamar a atenção do outro, de se aproximar. Os alunos querem ficar juntos, conversar, brincar e interagir; mas desde o momento em que entram na escola eles são separados por sexo nas filas, nas salas de aula, no pátio.

Assim, os conflitos que surgem entre meninos e meninas constituem, não raro, uma forma de aproximação com aspectos lúdicos: são os "jogos de gênero", na feliz expressão de Tânia Mara Cruz e Marília Pinto de Carvalho (2006: 142):

\footnotetext{
A prática de aproximação baseada em relações conflituosas provinha de uma necessidade de as crianças reequacionarem as relações de gênero no interior daquela cultura escolar. A aproximação parecia ser possível principalmente por meio do conflito ou dissimulada como conflito, devido ao pressuposto de uma oposição entre os sexos e à bipolaridade entre os significados de gênero, tão marcantes em nossa sociedade. Azeite e vinagre, às vezes, queriam misturar-se, brincar juntos, fazer coisas que pareciam adequadas apenas para o outro, mas essas possibilidades deviam ser ativamente construídas e vinham carregadas de problemas, ambiguidades e desafios.
}

A escola e seus ritos: fila, sineta, hino, sala de aula, recreio, almoço, uso de 
crachá para ir ao banheiro...

Os banheiros da escola possuem pictogramas na porta que sinalizam, na divisão masculino/feminino, os construtos de gênero: mictório para os meninos e compartimentos fechados com portas e trincos para as meninas. Essa arquitetura dos banheiros - na qual homens urinam em pé, publicamente, ao lado de outros homens, e a mulher sentada, em um espaço fechado e privado - funciona como uma "tecnologia de gênero", segundo Paul B. Preciado (2002), reafirmando socialmente modelos hegemônicos de masculinidade e feminilidade:

Os mictórios não são enclausurados em cabines fechadas, mas em espaços abertos ao olhar coletivo, uma vez que urinar em pé é uma atividade cultural que gera laços de sociabilidade compartilhados por todos aqueles que, ao fazê-lo publicamente, são reconhecidos como homens. (PRECIADO, 2002: 16, tradução nossa) ${ }^{6}$

Geralmente são os meninos que ultrapassam a fronteira simbólica delimitando esses espaços e vão até a porta do banheiro feminino conversar com as meninas. Quando descobertos, são advertidos por escrito pela escola.

As meninas passam boa parte do recreio nesse espaço, frente ao espelho, penteando-se e maquiando-se. Se para os homens o mictório participa dessa "arquitetura de gênero", demarcando formas de sociabilidade masculina heterossexual, para a mulheres é o espelho que participa da performance constitutiva da feminilidade: "Ao sair da cabine reservada para a excreção, o espelho, reverberação do olho público, convida o retoque da imagem feminina sob olhar controlador de outras mulheres" (PRECIADO, 2002: 17, tradução nossa)7.

O uso desses espaços tão estritamente demarcados traz um julgamento baseado nos construtos de gênero: marcas de pés no tampo do vaso sanitário do banheiro feminino são severamente repreendidas: "Isto não é coisa de menina! Depois, falam dos meninos”. Já quando se trata de um vaso sanitário entupido no banheiro masculino porque resolveram atirar-lhe uma fruta, os meninos não são repreendidos.

É nesse espaço, também, que comumente se manifestam questões relativas à sexualidade, tão silenciadas na escola. Um fato causou espanto entre os professores: um preservativo no banheiro das meninas. "De quem será?!", "Como veio parar aqui?!”, “Como vamos resolver?!” A equipe gestora optou por manter sigilo sobre o ocorrido, revelando a dificuldade em abordar questões referentes a corpo e sexualidade na escola.

Outro fato: um aluno de seis anos segue a coleguinha, da mesma idade, para o banheiro das meninas e, ao ser surpreendido, sai correndo. A família da aluna, ao tomar conhecimento do ocorrido por meio da menina, vai até a escola e exige que a direção tome providências porque a conduta do aluno foi "perigosa" - além de tê-la "constrangido", poderia ter "abusado" da mesma. A escola aciona o Conselho Tutelar e o aluno é encaminhado a um psicólogo para acompanhamento.

\footnotetext{
${ }^{6}$ No original: "Por ello, los urinarios no están enclaustrados en cabinas opacas, sino en espacios abiertos a la mirada colectiva, puesto que mear-de-pie-entre-tíos es una actividad cultural que genera vínculos de sociabilidad compartidos por todos aquellos, que al hacerlo públicamente, son reconocidos como hombres".

7 No original: "Al salir de la cabina reservada a la excreción, el espejo, reverberación del ojo público, invita al retoque de la imagen femenina bajo la mirada reguladora de otras mujeres".
} 


\section{Os usos sociais do espaço e a divisão sexual do trabalho}

A Equipe de Apoio, composta por profissionais de diferentes áreas - zeladores, faxineiros, inspetores e cozinheiras -, possuem funções regulamentadas pelo Regimento Interno da Secretaria de Educação.

As três zeladoras têm como atribuições cuidar da manutenção do patrimônio material, não permitindo que danifiquem, sujem ou se deteriorem as instalações da escola. Entretanto, por não realizarem as atividades do cargo - tais como trocar lâmpadas, carrapetas, maçanetas, entre outras -, as zeladoras são desviadas de função pela diretora com a anuência da Secretaria de Educação para exercer a função de inspetoras de disciplina.

Esse desvio de função se deve à própria divisão sexual do trabalho, pois essas atividades são entendidas por elas mesmas como típicas do sexo masculino: como explicou uma zeladora, "(...) não tive capacitação para tal função. Porque homens já nascem com esse instinto de capacidade". Com esse mesmo argumento, de que há atividades específicas para homens e mulheres, o auxiliar de serviços gerais - encarregado de varrer o pátio interno e externo, limpar as carteiras e o banheiro reservado para os meninos - nos explicou durante a conversa: “(...) que não leva jeito para limpeza, mas que é pau pra toda obra”, demonstrando certo constrangimento com relação à sua função. $\mathrm{E}$ a auxiliar diz que fica encarregada "da limpeza fina, como retirar a poeira das mesas, encerar e limpar o banheiro das meninas, porque vasculhar o teto e varrer pátio é serviço pesado, tem que ser homem".

Ao considerarmos a divisão sexual do trabalho baseada nesses construtos de gênero, não deixa de ser significativa a reflexão feita pela zeladora em desvio de função. Tempos depois da primeira conversa - na qual questionamos as funções de seu cargo e as funções que ela de fato exercia - ela nos abordou com a seguinte questão: "não é que eu fui pra casa e fiquei pensando que dou um duro danado olhando as crianças enquanto poderia estar lá, tranquila, dando umas marteladas com o prego na parede?!", fazendo o gesto de martelar o ar. Na sequência, disse que iria retornar para as funções do cargo.

Os inspetores de disciplina - dois homens e duas mulheres, responsáveis pela entrada e saída dos alunos, do cumprimento dos horários e das normas disciplinares da escola, assim como do trânsito de alunos fora da sala de aula - são divididos pela diretora da seguinte forma: um do sexo masculino e um do sexo feminino para cada segmento, com a função de atender as salas e acompanhar os alunos no pátio. No entanto, as atividades realizadas por eles diariamente revelam que estas também são definidas pelas relações de gênero: por exemplo, nos eventos de entretenimento esportivo da escola, é sempre o inspetor que acompanha os alunos e alunas; já nos passeios culturais a preferência é pela inspetora. Também na resolução de conflitos, os inspetores é que são chamados pelos professores; já na acolhida aos alunos no período de adaptação, as inspetoras é que são as encarregadas.

Como na sociedade kabyle, descrita em suas relações sociais e simbólicas por Bourdieu (1999), em que a construção simbólica da diferença masculino/feminino é baseada em uma série de oposições homólogas, como alto/baixo, quente/ frio, seco/úmido; na divisão do trabalho dos inspetores da escola é possível observar a construção da diferença em outras oposições, como pesado/leve, confronto/acolhimento, bruto/sensível, esporte/cultura. Essa divisão, mesmo que 
implícita, é incorporada pelos alunos e evidenciada no momento em que eles querem resolver algum problema. Por exemplo, quando se trata de passeio esportivo ou cultural, ou, ainda, em situações de conflitos, sem qualquer informação expressa fornecida pela escola sobre qual inspetor procurar para tais situações, eles se dirigem aos "respectivos" inspetores para resolver a questão. Assim, quando uma criança se machuca, ela "naturalmente" procura a inspetora Jane em vez de procurar o inspetor Beto.

A cozinha, tradicionalmente um espaço predominantemente feminino, conta com quatro cozinheiras. Os homens circulam pouco ali, somente quando solicitados. Ao entrarem, mesmo que seja para fazer pequenos reparos, como trocar uma carrapeta, eles agem com extrema cerimônia, desajeitados no andar e, ao terminar, se retiram rapidamente. Apesar do acesso à cozinha ser restrito, podendo entrar somente pessoas autorizadas, esse fato não explica o comportamento dos funcionários do sexo masculino, que demonstram falta de intimidade com esse espaço, onde parecem não se sentir à vontade. Como também observou Bourdieu (1999: 101) em relação à casa kabyle, notamos na escola a divisão simbólica do espaço a partir da oposição masculino/feminino: a cozinha é o local onde as mulheres permanecem até durante as suas refeições, enquanto os homens passam a maior parte do tempo no solário, local onde realizam suas refeições.

As quatro cozinheiras, encarregadas de preparar a alimentação e responsáveis também pela organização do refeitório e da despensa, passam a maior parte do tempo na cozinha. Quando recebem uma visita inesperada, dizem, um tanto constrangidas, que estão "daquele jeito": vestidas com roupas brancas e largas, unhas sem pintura, rosto sem maquiagem e cabelos cobertos por touca. "Daquele jeito", ou seja, bem diferente do momento em que chegam na escola - arrumadas, maquiadas, cabelos soltos... Para começar a trabalhar elas precisam investir tempo mudando a vestimenta, prendendo os cabelos e tirando as bijuterias, como se tivessem que se descaracterizar, perdendo os costumeiros sinais diacríticos que constituem socialmente a feminilidade.

Como nota Michelle Perrot (2005), referindo-se à preocupação com a aparência, que objetifica a mulher,

\footnotetext{
A mulher é, antes de tudo, uma imagem. Um rosto, um corpo, vestido ou nu. A mulher é feita de aparências. E isso se acentua mais porque, na cultura judaico-cristã, ela é constrangida ao silêncio em público. Ela deve ora se ocultar, ora se mostrar. Códigos bastante precisos regem suas aparições assim como as de tal ou qual parte de seu corpo. Os cabelos, por exemplo, condensam sua sedução. (PERROT, 2005: 49)
}

Geralmente, quando chamadas para fotos, a primeira coisa que as cozinheiras fazem é tirar a touca dos cabelos, como se o cabelo fosse a moldura do rosto; mais: como se fosse uma forma de resgatar um pouco da feminilidade perdida sob o uniforme exigido nos afazeres da cozinha. Historicamente, em nossa tradição cultural, os cabelos têm uma importância simbólica nos construtos de gênero: "Os cabelos são a mulher, a carne, a feminilidade, a tentação, a sedução, o pecado", nos lembra Perrot referindo-se às mais diversas práticas - do uso do véu, como sinal de dependência; passando pelo corte rente, como ato de emancipação; até a prática da tosquia, em público, como forma de punição (PERROT, 2005: 49-62).

A divisão sexual do trabalho que estrutura simbolicamente as funções e relações entre os funcionários da escola também estrutura simbolicamente as funções e relações entre o corpo docente: até junho de 2017, o primeiro segmento do Ensino Fundamental ( $1^{\circ}$ ao $5^{\circ}$ ano) era composto única e exclusivamente por mulheres. No entanto, a chegada de um professor para assumir uma turma nos primeiros anos do Ensino Fundamental, universo social eminentemente feminino, 
causou certo estranhamento.

Um professor fora de lugar... um incômodo tão evidente que não necessitou nem mesmo ser expresso verbalmente.

As relações de gênero marcam a interação entre os docentes, fato especialmente perceptível durante as conversas informais na sala dos professores. Assim, observamos em diversas ocasiões que, quando as professoras ( do $1^{\circ}$ ao $9^{\circ}$ ano) conversavam sobre determinadas questões - o comportamento dos alunos e as dificuldades de aprendizagem, por exemplo - os professores (do $6^{\circ}$ ao $9^{\circ}$ ano) demonstravam um desinteresse mais ou menos velado, não raro retirando-se discretamente da sala ou abstendo-se de qualquer comentário. Apenas as professoras seguiam dialogando e, como se não percebessem o desinteresse, insistiam para que opinassem sobre as questões 8 .

Um fato que de tão corriqueiro não deixa de ser significativo: ao requerer a opinião dos professores como forma de legitimar suas falas, parece que as professoras não percebem sua posição nessa relação de dominação. Evidencia-se, assim, a violência simbólica, definida por Bourdieu (2003: 7-8) como aquela violência exercida mediante o consentimento tácito de suas vítimas, mesmo que inconsciente:

(...) violência suave, insensível, invisível a suas próprias vítimas, que se exerce essencialmente pelas vias puramente simbólicas da comunicação e do conhecimento, ou mais precisamente, do desconhecimento, do reconhecimento ou, em última instância do sentimento.

Em suma, pode-se dizer que a percepção de mundo das crianças com relação a divisão sexual do trabalho tem início na infância, durante o processo de socialização, e a escola reproduz essa divisão. Na escola, as relações de gênero geralmente são determinantes para que alunos e alunas, funcionários e funcionárias, realizem algumas atividades e utilizem determinados espaços. Mesmo que construída de forma invisível, a partir de relações simbólicas, a escola possui atribuições específicas para homens e mulheres, como, por exemplo, o preparo da alimentação, destinado às mulheres, e os de zeladoria, destinado aos homens.

Como nota Guacira Lopes Louro (1997: 58), pela sua arquitetura, regulamentos, organização, avaliações, vigilância e ritos o "prédio escolar informa a todos/as sua razão de existir. Suas marcas, seus símbolos e arranjos arquitetônicos "fazem sentido", instituem múltiplos sentidos, constituem distintos sujeitos". Tudo contribui para a produção e a hierarquização das diferenças entre os indivíduos.

Como ficam as crianças e os profissionais que não se reconhecem, não se identificam ou não se encaixam nesse espaço?

\section{Apurando o ouvir: "O caderno está muito caprichado", "Ainda dá tempo de corrigir"}

Como vimos, se a (re)produção das relações de gênero, na escola, tem início nos ritos escolares, nos usos sociais do espaço e na divisão sexual do trabalho, esse processo incessante de construção da diferença masculino/feminino continua mediante as práticas pedagógicas em sala de aula.

Um episódio revelador dos meandros desse processo ocorreu logo no início da pesquisa, durante a visita de uma professora da equipe gestora na sala de aula

${ }^{8}$ Quando realizamos a pesquisa o corpo docente era composto por 15 professores: 9 mulheres e 6 homens. A maioria oriunda de outras localidades do município ou mesmo de outras cidades. 
de uma turma do primeiro segmento do Ensino Fundamental. Ao olhar o material escolar dos alunos, a professora em questão elogiou o caderno de um menino fazendo o seguinte comentário: "O caderno está muito caprichado", e a professora da turma, que estava em sua mesa, retrucou ironicamente: "Ainda dá tempo de corrigir”.

Reencontramos aqui a ideia de que cadernos caprichados, com letra legível, uso de canetas coloridas, encapado, sem amassos ou rabiscos são cadernos de "menina".

Segundo Carvalho (2012: 410), os cadernos têm sido um dos elementos fundamentais na avaliação dos alunos, implicando um juízo de valor baseado nos construtos de gênero que atribuem ao feminino características como "limpeza, organização, cores, capricho, decalques e enfeites, letra bonita" e, ao masculino, características como "desleixo, letras esgarçadas, desorganização e sujeira". Como observou a autora, os professores frequentemente avaliam os cadernos privilegiando aspectos estéticos e não propriamente a aprendizagem, o que acarreta uma contradição: a escola exige um caderno esteticamente bonito e concomitantemente entende que estas características são inerentes ao feminino. Consequentemente, meninos não podem ter cadernos caprichados. Não por acaso, no episódio acima descrito, a professora, ao se deparar com o caderno de um menino com as características geralmente atribuídas ao feminino, apto para uma boa avaliação em termos estéticos, de forma implícita colocou em questão a masculinidade do aluno.

Assim, se o bom desempenho escolar está implicitamente relacionado às características consideradas "femininas", os meninos deparam-se com uma situação paradoxal, na qual o atendimento às exigências escolares os coloca em contradição com os modelos hegemônicos de masculinidade, que exigem demonstrar força, coragem, rebeldia. O comportamento esperado para meninos e meninas é divergente no sentido de que os primeiros devem, ainda que implicitamente, apresentar falta de capricho, mal comportamento, domínio entre os grupos, como afirmação social de sua masculinidade; e, as meninas, a delicadeza e o capricho como afirmação social de sua feminilidade.

Um episódio semelhante, que ilustra a importância conferida à aparência das atividades realizadas pelos alunos, ocorreu em uma reunião pedagógica - momento no qual os professores se reúnem com os orientadores para o planejamento e avaliação de suas práticas pedagógicas. Durante a reunião foram discutidos os critérios avaliativos para a correção dos trabalhos escolares realizados em casa. Segundo a professora Beth, as meninas apresentavam o trabalho com "capricho e organização", enquanto os trabalhos de alguns meninos apresentavam "conteúdo OK, mas parecia estar amassado, assim eu não poderia dar a mesma nota”. Ou seja: o conteúdo atendia aos objetivos estabelecidos pela professora, mas como sua apresentação não atendia aos aspectos estéticos exigidos implicitamente pela escola - aspectos estes considerados socialmente atributos femininos - o trabalho "parecia estar amassado".

Ao falar sobre como avaliava os trabalhos dos alunos em sala de aula, a mesma professora afirmou:

Em sala de aula, os trabalhos em grupo também são divididos entre meninos e meninas, mas os meninos, na maioria das vezes, têm mais dificuldades, apresentam trabalhos sem capricho, com folhas arrancadas de cadernos, ainda com as pontas, as meninas são mais atentas e empenhadas.

Deparamo-nos com essa visão - de que os meninos seriam desorganizados e 
sem capricho, enquanto as meninas seriam mais empenhadas - na fala de inúmeros docentes, como a da professora Suzi:

\begin{abstract}
Tento dar maior visibilidade ao conteúdo, mas não é justo com as meninas avaliar da mesma forma. Eles sempre tiram notas menores por falta de capricho. É minha função ensinar desde cedo que a aparência é fundamental, seja na escola ou futuramente em um emprego.
\end{abstract}

É nesse sentido que os “trabalhos amassados" devem ser compreendidos: durante a pesquisa percebemos que ao se verem obrigados a se comportar de acordo com os modelos hegemônicos de masculinidade, os meninos acabam evitando entregar trabalhos e cadernos caprichados como forma de reafirmar socialmente sua masculinidade diante de seus pares e professores.

Como ressalta Carvalho,

Sem dúvida, há aqui uma questão complexa a ser investigada na sociabilidade entre os próprios meninos, a fim de avaliar em que medida as pressões entre pares, a partir de certos referenciais de masculinidade e de heterossexualidade, interferem em seu comportamento diante da escola, da professora, do desempenho escolar e, por consequência, também na forma de seus cadernos. (CARVALHO, 2012: 409)

Além do conteúdo e da relevância do caráter estético dos trabalhos apresentados, o comportamento é outro fator preponderante no processo avaliativo. No caso dos meninos, estes aspectos influem negativamente na atribuição de notas, uma vez que são considerados menos comportados e menos organizados do que as meninas. Assim, comportamentos considerados "normais" para meninos são reprovados em meninas: uma briga causada ou um palavrão proferido por uma aluna estão sujeitos a sanções mais severa do que se causada e proferido por um aluno.

Observamos duas situações análogas que provocaram reações absolutamente distintas por parte da mesma professora: na primeira, dois meninos que se agrediram fisicamente foram encaminhados pela professora Clara para a direção e ambos receberam apenas uma advertência sem maiores comentários; na segunda, duas meninas discutiram no pátio da escola fazendo uso de palavrões e a mesma professora as repreendeu, mostrando-se desapontada com tal atitude, e convocou os pais para conversarem sobre o mau comportamento apresentado pelas alunas. Ou seja, a agressão física entre os meninos - alvo apenas de uma advertência - não suscitou a mesma punição que os palavrões proferidos pelas meninas, que foram punidas com mais severidade, chamando-se a família.

Conforme nota Louro (1994: 37-38), os comportamentos que se esperam baseados no sexo biológico dos indivíduos estão tão "naturalizados" socialmente, que causa estranheza quando ocorre um "desvio": "(...) há comportamentos, falas, gestos, posturas físicas, além de atividades e funções, que são socialmente entendidas como adequadas, "naturais", apropriadas, para as mulheres ou para os homens".

De fato, espera-se comportamentos diferentes de alunos e alunas, como demonstra a fala da professora Suzi:

As meninas aprendem muito mais rápido, porque elas prestam atenção, os meninos não têm sossego. Eles são até mais espertos, mas são preguiçosos, se recusam a fazer os deveres que chamam de "chatos", que as meninas fazem.

Nota-se frequentemente que uma avaliação positiva está associada ao comportamento e não a aprendizagem em si. A professora Clara, que tratou de formas distintas os conflitos entre meninos e meninas, ao falar sobre o rendimento dos alunos afirma: 
Sem dúvida, a maioria das meninas são mais comportadas, caprichosas, interessadas e estudiosas, os meninos têm mais dificuldades, em geral com a aparência dos trabalhos, e até mesmo em comportar-se em sala de aula para aprender o conteúdo. Toda regra tem exceções, já tive alunas muito agitadas que parecem meninos e alunos muito interessados que parecem meninas, mas são raros.

Evidentemente não se trata, aqui, de responsabilizar os docentes pela (re) produção dos estereótipos de gênero (ou raça, classe e outros marcadores sociais da diferença) em suas práticas pedagógicas, mas tão somente de perceber o quanto a naturalização dessas diferenças socialmente construídas possibilitam trajetórias de maior ou menor sucesso escolar para meninos e meninas.

Assim, ao explicar como avaliava os alunos, a professora prossegue: "Eu avalio o comportamento em sala de aula e os cadernos todos os dias, diariamente". A redundância - "todo dia, diariamente" - não deixa de ser significativa, sugerindo o quanto os critérios de avaliação parecem levar mais em conta aspectos disciplinares do que do que propriamente o processo de aprendizagem em si.

E recorrente, entre os professores, a ideia de que os meninos são indisciplinados "por natureza" e por isso "não aprendem". Em conversa com a professora Lena no refeitório, percebemos sua preocupação em relação ao aumento do quantitativo de meninos na escola: "Você já reparou que nesta escola tem mais meninos do que meninas? As meninas são aprovadas e saem da escola e os meninos vão ficando. Daqui a pouco será uma escola de meninos. Será um caos”.

Ideia que reencontramos na fala da professora Suzi:

\begin{abstract}
As meninas, elas são bem mais centradas que os meninos. Na hora da explicação, geralmente elas estão sempre olhando atentas, os meninos às vezes se distraem, alguns, apesar da turma ser bem participativa, atenta, entendeu? Raramente tem esses casos, na maioria são os meninos que se distraem no momento da explicação. $\mathrm{Na}$ hora que estão realizando a atividade ou avaliação, eu percebo que as meninas já estudaram em casa e se prepararam, entendeu? Tem as exceções, mas a maioria que vem despreparada para a avaliação é geralmente de meninos.
\end{abstract}

Notamos ao longo da pesquisa que os critérios para avaliar o desempenho dos alunos são bastante subjetivos e baseiam-se, com frequência, na simbólica sexual. A escola espera que as meninas apresentem letra e cadernos caprichados e conteúdo mais detalhado em seus trabalhos, atributos que elevam suas notas. Considerados femininos, esses atributos, segundo as professoras, de modo geral não são observados entre os meninos, que para corresponderem ao modelo hegemônico de masculinidade - exigido e ao mesmo tempo penalizado na escola - elaboram suas produções de forma mais sucinta e menos cuidada, sem muito capricho.

Para Bourdieu (2003: 16), a simbólica sexual é tematizada através de um conjunto de oposições homólogas que são simultaneamente concordes - "para se sustentarem mutuamente, no jogo e pelo jogo inesgotável de transferências práticas e metáforas" - e divergentes - "para conferir, a cada uma, uma espécie de espessura semântica, nascida da sobredeterminação pelas harmonias, conotações e correspondências". Assim, a consonância entre as estruturas incorporadas e as estruturas objetivas faz com que a construção simbólica da diferença masculino/feminino aparente ser algo natural: "parece estar na ordem das coisas" (idem: 17).

$\mathrm{Na}$ escola, esses esquemas de pensamento parecem assentados em uma série de outras oposições que vão construindo a diferença masculino/feminino: desorganização (masculino)/organização (feminino); feio (masculino)/bonito (feminino); sujo (masculino)/limpo (feminino); amassado (masculino)/desamassado 
(feminino); bagunçado (masculino)/caprichado (feminino). E quando um aluno ou aluna fogem a essa percepção - a esses "vastos esquemas de pensamentos impensados", segundo expressão do autor (ibidem) - questiona-se implicitamente sua masculinidade e/ou feminilidade.

Em suma, a (re) produção das relações de gênero na escola incide nas trajetórias escolares de meninos e meninas, acarretando, para os primeiros - que necessitam corresponder ao modelo hegemônico de masculinidade - um elevado número de reprovação por indisciplina; e para as segundas - cobradas para corresponder ao modelo hegemônico de feminilidade -, um comportamento mais dócil e submisso. Conforme observa Carvalho (2012), se os construtos de gênero levam um maior número de meninos ao fracasso escolar, as meninas, em virtude do capricho, organização e bom comportamento são aprovadas em maior número, ainda que apresentem dificuldades de aprendizagem. Como ilustra a fala da professora Lena, "só dou ponto para quem merece".

Assim, "trabalhos amassados" e "cadernos caprichados" revelam percepções diferenciadas e classificatórias de gênero: e, caso haja "desvios" comportamentais, "ainda dá tempo de corrigir".

\section{Focos de resistência}

Se a (re) produção das relações de gênero na escola constitui um processo constante que transcorre mediante os ritos escolares, os usos sociais do espaço, a divisão sexual do trabalho e as práticas pedagógicas, entre outras práticas sociais, os focos de resistência a essas relações de poder também se manifestam, pois, como dizia Foucault (1988: 106), é inerente às relações de poder a possibilidade de resistência:

As resistências não se reduzem a uns poucos princípios heterogêneos; mas não é por isso que sejam ilusão, ou promessa necessariamente desrespeitada. Elas são o outro termo das relações de poder; inscrevem-se nessas relações como o interlocutor irredutível.

Procuramos, na escola, por esses focos de resistência que animam os corpos indóceis das crianças e jovens. Corpos que resistem, pulsam, insistem...

Como o de Miriam. Um dia a jovem passa a utilizar o sobrenome de um terrorista norte-americano ao assinar suas provas, trabalhos e outras atividades. Apologia ao terrorismo? Ameaças nas entrelinhas? Do nosso ponto de vista essa atitude constitui uma forma de resistência ao julgamento efetuado pelos professores acerca do seu modo de vestir, incômodo evidenciado no comentário de uma professora em um Conselho de Classe ao se referir à aluna: "ela não sabe o que é, cada dia vem de um jeito, psicopata!" O incômodo: o fato de a aluna alternar seu modo de vestir-se, indo à escola um dia com trajes considerados masculinos cabelos presos por debaixo do boné, calça jeans larga e sem bijuterias; e, noutros, indo com trajes considerados femininos - cabelos soltos, saia e batom. Os alunos resistem... e a forma que Miriam encontrou foi justamente condensar simbolicamente, ao assinar suas atividades, a identidade que lhe havia sido conferida pela escola: "psicopata".

Outro caso: nos corredores da escola, a professora Beth se depara com Joyce e diz em voz alta: "Olha ela! Hoje resolveu ser outra coisa!" Ao observar a aluna, percebemos que ela também estava vestida com trajes considerados masculinos - calça jeans, boné, chuteira e cabelo preso. Na reunião pedagógica, Joyce foi descrita pela professora como uma menina que não era "caprichosa" com seu material escolar. Uma chuteira faz toda a diferença... 
Na escola, os trajes reafirmam modelos hegemônicos de masculinidade e feminilidade, como indica a fala da professora, que classifica as meninas segundo suas roupas como "patricinhas", "meninas normais" e "meninas que se vestem como meninos":

As patricinhas têm brilho diferente, usam acessórios, brincos, colares, unhas pintadas, roupas sempre limpas e sapatos que combinam com a roupa, as meninas normais usam o uniforme sem acessórios ou com poucos, tem algumas que se vestem como menino.

E na intenção de compreender o que seria, para a professora, as meninas "que se vestem como meninos", obtivemos a seguinte resposta: "Sei lá, usa bermuda larga, camisa amarrotada e boné, às vezes vão de chinelo para a escola, acho que ainda não se definiram".

Nessa escola é permitido o uso de bonés, calças e bermudas para meninas, mas, ao que parece, as professoras esperam que esses acessórios e vestimentas venham com os sinais diacríticos de feminilidade segundo a lógica construída em nossa sociedade: que sejam cor de rosa, ou tenham rendas, bordados, lantejoulas etc. Os alunos e alunas que não se encaixam nos modelos hegemônicos de masculinidade e feminilidade criam estratégias para subverter as normas. Ao mudarem de estilo todos os dias - um dia vestindo-se com trajes considerados masculinos; noutros, com trajes considerados femininos - Miriam e Joyce demonstram uma fluidez que tensiona os estereótipos de gênero. Focos de resistência: um modo de não se afirmar nada; ou de mostrar que há várias formas de ser homem e de ser mulher; ou, ainda, várias formas não binárias de existência.

Focos de resistência também entre os docentes, como a professora Sônia, que não se eximiu de abordar, em tempos de projetos conservadores como o "escola sem partido" e discursos sobre "ideologia de gênero", questões sobre gênero e sexualidade quando questionada em sala de aula:

\begin{abstract}
O trabalho surgiu a partir de algumas perguntas que os alunos fizeram sobre sapatão, gay, lésbica. Só que, só as meninas fizeram a pesquisa e alguns meninos participaram do debate. Os meninos do grupinho de trás não se interessaram nem no momento da discussão, ainda fizeram piadas e ironizaram questões trazidas pelos colegas, como na fala de um deles - "eu não gosto dessas conversas não".
\end{abstract}

Conforme explicaria, a pesquisa versava sobre a "sexualidade na espécie humana" e os alunos deveriam pesquisar os seguintes tópicos: "as diferenças sexuais; as diferentes opções sexuais; e os problemas e questões relativas às diferenças de gênero, papel social, respeito às diferenças, desigualdades e liberdade de expressão".

Não nos interessa, aqui, discutir a adequação ou inadequação dos termos empregados - como "opção" sexual, por exemplo - mas sim discutir os desdobramentos da ação entre a comunidade escolar. Entre os alunos, como nos relataria Sônia, houve atitudes preconceituosas por parte de um grupo, que se manteve à margem da discussão: "fizeram piadas e ironizaram questões trazidas pelos colegas”. Poder-se-ia questionar em que medida a promoção do debate apenas com os alunos interessados constituiria uma ação eficiente no combate ao preconceito na escola; ou se sinalizaria, ainda que involuntariamente, ser este um tema de pouca relevância. Contudo, esse também não é o nosso objetivo nesse artigo.

A pesquisa culminaria com apenas um cartaz confeccionado por um grupo de alunas.

Ainda que não tenha tido o alcance desejado pela professora, que não conseguiu mobilizar a turma para a discussão do tema, a iniciativa despertou reações contrárias por parte de alguns pais e outros membros da comunidade escolar, que 
questionaram as temáticas abordadas em sala de aula. E logo acionou-se o Conselho Escolar, que é um órgão integrado por professores, pais de alunos, alunos e funcionários com o objetivo de promover a democratização na tomada de decisões relativas a escola. O Conselho é composto por pessoas de diferentes classes e gerações, predominando, neste, pessoas oriundas das classes populares, de religião evangélica e com faixa etária acima de 50 anos.

Durante a reunião, depois das considerações de alguns de seus membros, foi proposto que os professores só abordassem temáticas como reprodução, gravidez indesejada, contágio por infecções sexualmente transmissíveis e afins - questões cuja finalidade, justamente, é a de regular e controlar a vida da população (FOUCAULT, 1988). Desse modo poder disciplinar e biopolítica entrelaçam-se na escola, o primeiro mediante a vigilância e o controle constantes; e o segundo mediante a configuração do próprio currículo (VEIGA-NETO: 2013).

Mas a proposta do Conselho foi além da censura às questões sobre relações de gênero, identidade de gênero e orientação sexual; foi solicitado, também, que a abordagem sobre reprodução, gravidez indesejada e doenças sexualmente transmissíveis ocorresse com a separação dos alunos por sexo, alegando-se que seria constrangedor, para as meninas, ficarem juntas com os meninos nessas aulas. É escusado dizer que essa proposta vai de encontro ao papel da educação, que seria ampliar e não restringir horizontes, constituindo um imenso retrocesso.

Precisávamos ouvir Sônia sobre as propostas do Conselho: qual seu ponto de vista sobre essa decisão? Por meio de uma "escuta ativa", observando as emoções que acompanharam sua fala, procuramos restituir, na íntegra, o que nos foi dito:

\begin{abstract}
Eu debati bastante com o Conselho, porque não concordo com essa decisão de que devo me manter só na temática reprodução, abordar somente assuntos relacionados a doenças e contágios, pelo simples fato de que o mundo hoje não é só isso. As crianças têm um contato por meio da TV, da realidade, de novelas, como a diversidade de gênero e eu acredito que é trabalhando, trazendo esse tema para sala de aula como forma de pesquisa, buscando conhecer e entender, é que vamos criar cidadãos que se respeitem, buscando não se ter aquela mentalidade homofóbica, pois o mundo hoje em dia traz para as crianças esse assunto, mesmo que a escola não forneça esse tipo de realidade para ela. Mas elas têm acesso pelas ruas, pela TV, novelas, onde assistem essas questões. Então, às vezes, eu posso ter um aluno com indecisões de gênero ali dentro da sala e, a partir do momento em que eu só fale homem e mulher, eu bato na tecla que só há essa possibilidade, que a sociedade só vai aceitar se vocêfor homem se casar com uma mulher, se você for mulher se casar com um homem. Que tipo de cidadão eu vou estar formando? O dever da escola é informar ao aluno e formar esse cidadão para um futuro. Por isso, eu não concordei.
\end{abstract}

Sônia nos explicaria que a preocupação com essas questões teria surgido a partir da realização de um curso sobre diversidade sexual e gênero na escola: " $\hat{E}$ baseada nessa formação que eu procuro trazer para os meus alunos essas questões de gênero". Ao indagarmos se o episódio com o Conselho a faria desistir de abordar essas questões com seus alunos, ela foi enfática:

\begin{abstract}
A princípio não pretendo mudar minha prática pedagógica. Pretendo sim, aperfeiçoar a maneira como eu posso me dirigir aos alunos, os termos, uma forma mais correta de abordar esses temas. Acho que fiquei um pouco frustrada pelo fato de ter sido repreendida por uma coisa que as crianças vivenciam na realidade (...). Eu não estou induzindo meus alunos à homossexualidade, mas sim buscando que eles conheçam e entendam, para se respeitarem. Por isso não penso em mudar e pretendo defender essa ideia, essa prática minha, levando, se for necessário, ao Conselho Escolar para conseguir uma forma de propagar a informação e o conhecimento aos meus alunos.
\end{abstract}

Focos de resistência: percebemos que Sônia continuará acolhendo as inquietações de seus alunos, abordando em sala de aula temas que os interessam, sem 
eximir-se de discutir questões relacionadas a corpo, gênero e sexualidade.

Como defende Marlucy Paraíso (2016), o currículo deve ser um território para hospedar as diferenças, afirmar a vida e multiplicar os encontros:

\begin{abstract}
Lutamos para que as relações de gênero e as diferentes formas de viver a sexualidade saiam do lugar do silêncio acomodado, dos ensinamentos velados, das omissões covardes ou propositais, dos "turismos" inconsequentes nas escolas, para o centro das desnaturalizações e problematizações do masculino e do feminino, do heterossexual e homossexual nos mais diferentes currículos. (PARAÍSO, 2016: 25)
\end{abstract}

De certa forma foi o que Sônia fez: ao não concordar com a decisão do Conselho, debatendo com seus membros, Sônia demonstra que é preciso resistir contra o que nos oprime. Como afirma:

É importante hoje em dia tratar dessa diversidade de gênero na escola, não só abordar como a gente vinha fazendo, porque o mundo desses pais, dos professores, desses membros do Conselho, na idade deles, era um outro mundo diferente, uma realidade diferente da que nossos alunos vivem hoje. Então, eu acredito que a prática pedagógica deve se adequar a realidade dos dias de hoje para ser levada aos nossos alunos.

\title{
Considerações finais
}

Em sua descrição da casa kabyle, Bourdieu (1999) desvelou os mecanismos invisíveis da construção hierárquica da diferença masculino/feminino na constituição de seus espaços e nos seus usos sociais.

No entanto, como alerta o autor, dizer que há “construção" - construção simbólica, social, cultural e histórica de corpos, gêneros e sexualidades - não basta para compreender e, principalmente, combater os mecanismos invisíveis da dominação. É preciso analisar as condições sociais da construção hierárquica da diferença; em suas palavras, "as condições da construção das categorias de construção” (BOURDIEU, 2002: 231). Mas por outro lado e não menos importante, como ele mesmo enfatiza, dizer que há construção significa dizer, também, que haverá sempre lutas cognitivas a respeito do sentido das coisas e da "ordem" do mundo.

Defendemos nesse artigo a necessidade de descrever e analisar esses mecanismos de construção da diferença masculino/feminino na escola - nos usos sociais que fazemos de seus espaços, na divisão do trabalho e no modo como atribuímos as tarefas, em nossos discursos e em nossas práticas pedagógicas - posto que essas diferenças são traduzidas, socialmente, em desigualdades. Se o gênero é a forma por excelência de significar as relações de poder, como defende Scott (1995: 21), precisamos problematizar o modo como (re) produzimos explícita e, sobretudo, implicitamente, essas relações na escola.

As notas etnográficas que apresentamos aqui constituem uma tentativa de trazer à tona alguns aspectos do que está no mais "profundo e mais profundamente inconsciente da nossa experiência ordinária" como docentes; uma tentativa de pensar alguns desses "vastos esquemas de pensamentos impensados" que teimam em conformar nossos discursos e práticas sociais (BOURDIEU, 2002; 2003).

Para Geertz (2001: 65), que definiu a etnografia como uma "descrição densa" de relações sociais, o papel do etnógrafo seria inquietar: "Tranquilizar é tarefa dos outros; a nossa é inquietar”. (Ou perturbar os que aderem satisfeitos à doxa, supomos que diria Bourdieu...).

Não sabemos se logramos tal intento, mas certamente saímos, nós mesmas, mais inquietas dessa pesquisa do que quando a iniciamos, ao perceber, em nossas práticas pedagógicas e discursos, esses esquemas de pensamento que constroem 
a "ordem" do mundo - e que é preciso saber subverter, cotidianamente, com nossas alunas e alunos.

Recebido em 4 de junho de 2020.

Aceito em 30 de agosto de 2020.

\section{Referências}

BOURDIEU, Pierre. Nouvelles réflexions sur la domination masculine. Cahiers du Genre, 33 (2): 225-233, 2002.

BOURDIEU, Pierre. A Casa Kabyle ou o Mundo às Avessas. Cadernos de Campo, 8 (8): 147-159, 1999.

BOURDIEU, Pierre. A dominação masculina. Rio de Janeiro: Bertrand do Brasil, 2003.

BOURDIEU, Pierre. Esboço de autoanálise. São Paulo: Companhia das Letras, 2005 .

BOURDIEU, Pierre. A miséria do mundo. Petrópolis: Vozes, 2012.

BOURDIEU, Pierre. "Os excluídos do interior”. In: NOGUEIRA, Maria Alice; CATANI, Afrânio (orgs.). Escritos de Educação. 16ª ed. Petrópolis: Vozes, 2015. pp. 243-255.

CARVALHO, Marília Pinto. O conceito de gênero no dia a dia da sala de aula. Educação Pública, 21 (46): 401-412, 2012.

CARVALHO, Marília Pinto. Quem são os meninos que fracassam na escola? $\mathrm{Ca}$ dernos de Pesquisa, 34 (121): 11-40, 2004.

CARVALHO, Marília Pinto. Sucesso e fracasso escolar: uma questão de gênero. Educação e Pesquisa, 29 (1): 185-193, 2003.

CRUZ, Tânia Mara; CARVALHO, Marília. Jogos de gênero: o recreio numa escola de ensino fundamental. Cadernos Pagu, 26: 113-143, 2006.

FOUCAULT, Michel. Vigiar e Punir: nascimento da prisão. 42. ed. Petrópolis: Vozes, 2014.

FOUCAULT, Michel. História da sexualidade I. A vontade de saber. Rio de Janeiro: Edições Graal, 1988.

GEERTZ, Clifford. "Uma descrição densa: por uma teoria interpretativa da cultura”. In: A interpretação das culturas. Rio de Janeiro: LTC, 2015. pp. 3-24.

GERBER, Rose Mary. Mulheres e o mar: uma etnografia sobre pescadoras embarcadas na pesca artesanal no litoral de Santa Catarina, Brasil. Tese de Doutorado apresentada ao Programa de Pós-Graduação em Antropologia Social da Universidade Federal de Santa Catarina. Florianópolis, 2013. 
LÉVI-STRAUSS, Claude. "Introdução à Obra de Marcel Mauss". In: MAUSS, Marcel. Sociologia e Antropologia. São Paulo: EPU, 1974.

LOURO, Guacira Lopes. Gênero, sexualidade e educação: uma perspectiva pósestruturalista. Petrópolis: Vozes, 1997.

LOURO, Guacira Lopes. Uma leitura da história da educação sob a perspectiva do gênero. Projeto História, 11: 31-46, 1994.

OLIVEIRA, Roberto Cardoso de. O trabalho do antropólogo. Rio de Janeiro: UNESP, 2000.

PERROT, Michelle. Minha história das mulheres. São Paulo: Contexto, 2005.

PRECIADO, Beatriz. Basura/Gênero. Mear/Cagar. Masculino/Feminino. In: Parole de Queer blogspot, 2002. Arquivo digital. Disponível em https://paroledequeer.blogspot.com/2013/o9/beatrizpreciado.html. Acesso em 29/09/2020.

SCOTT, Joan. Gênero: uma categoria útil de análise histórica. Educação e Realidade, 20 (2): 71-99, 1995.

VEIGA-NETO, Alfredo. Biopolítica, normalización y educación. Pedagogía y Saberes, 38: 83-91, 2013.

WEBER, Girlaine. "Este caderno tá muito caprichado, ainda dá tempo de corrigir”: uma reflexão sobre a (re)produção das relações de gênero na escola. Dissertação (Mestrado em Educação). Petrópolis, Universidade Católica de Petrópolis, 2018. 


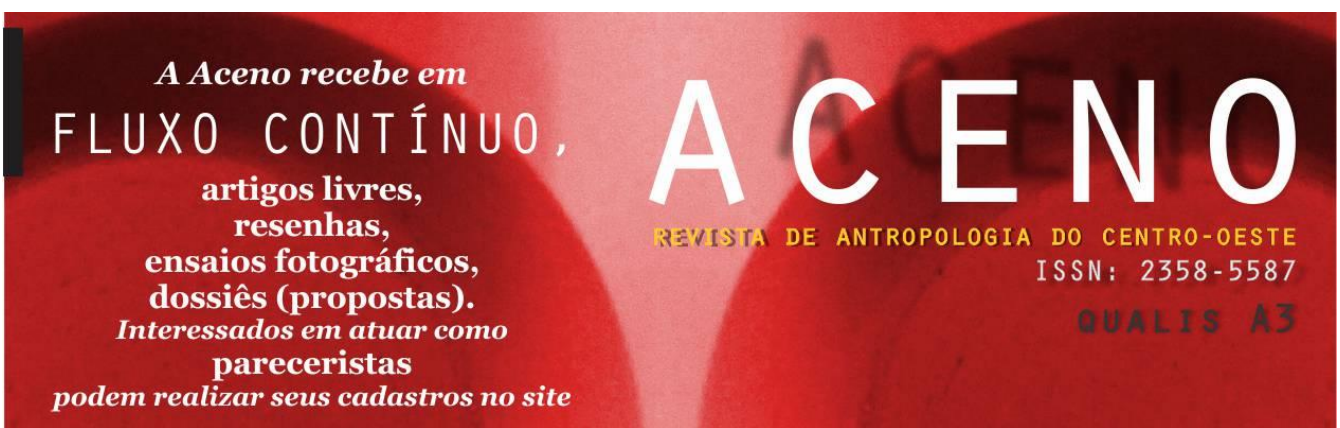

